Open Access

\title{
Retirement delay unified or differentiated-based on the interaction between pension deficit and labor market
}

Zou Tieding ${ }^{1}$ and Ye Hang ${ }^{2^{*}}$

*Correspondence:
yehang@China.com
${ }^{2}$ School of Economics, Zhejiang
University, Hangzhou, China
Full list of author information is
available at the end of the article

* Correspondence: yehang@China.com University, Hangzhou, China available at the end of the article

\begin{abstract}
Background: The pension deficit has been rapidly enlarging for more than a decade. If the retirement age is set at a low level, it might trigger a pensions crisis. Since the average life span of the Chinese has extended from 71 to 76 years old in last ten years, the feasibility of rising the retirement age has also been promoted.

Methods: This paper aims to construct a mathematical model for choosing a proper policy about raising retirement age on the basis of the interaction between shortage of pension funds and labor market. It has also conducted a simulation analysis over the economic efficiency and political feasibility of a uniformed or a differentiated retirement-age delay policy.

Results: Our findings show that it is up to how effective the pension deficit is closed, how many employments will be crowded out, and whether it is politically acceptable that the length and kind of the delay is decided. From the policy effect of raising retirement age, a soft approach to delaying retirement will be better than a tough one, and a differentiated method will be better than a uniformed one. The root cause for the inconsistency of the policy effect is the discrepancies in terms of wage rate and job fulfillment, brought by different human capital situations and individual differences of the insured. The shortage of pension funds can be more effectively closed, and the impact on new labor force will be reduced, if we employ a differentiated approach to delay retirement according to the pattern of human capital accumulation and the supply and demand status of labor force.
\end{abstract}

Conclusions: Based on the above research, Not only can the differentiated approach crowd out fewer new employees, but also it can acquire support from the majority of the insured. We must attach importance to the role of human capital investment in addressing pension and employment crises, especially the low- skilled labor, can get more vocational training and academic education.

Keywords: Pensions, Shortage of pension funds, The retirement delay, Labor market

\section{Background}

The pension deficit has been rapidly enlarging for more than a decade. The gap was 35.7 billion yuan in 2000, and it surged to 57.6 billion yuan in 2005, 70 billion yuan in 2011, and exceeded 100 billion in 2012. It is astonishingly expected to overpass 150 billion yuan. ${ }^{1}$ The shortage of pension funds is closely related to the growth of aging population. From 2012 to 2013, Chinese aging population over 60 increased from 194

(c) 2016 The Author(s). Open Access This article is distributed under the terms of the Creative Commons Attribution 4.0 International License (http://creativecommons.org/licenses/by/4.0/), which permits unrestricted use, distribution, and reproduction in any medium, provided you give appropriate credit to the original author(s) and the source, provide a link to the Creative Commons license, and indicate if changes were made. 
million to 202 million, accounting for $14.8 \%$ of the entire population. ${ }^{2}$ On the one hand, the growth of the aged population has increased the government's spending on pensions. On the other hand, the dwindling young population has limited the revenue of pensions. If the retirement age is set at a low level, it might trigger a pension crisis (Zeng 2005). Compared with European and US retirement ages, which are usually between 65 and 67, China's retirement ages-men at 60 years old and women at 50 years old-are apparently at low level (Blöndal and Scarpetta 1997; Xu et al. 2003). ${ }^{3}$ In order to avoid the deterioration of the pension crisis, adjusting the retirement age becomes necessary (Song 2010). Since the average life span of the Chinese has extended from 71 to 76 years old in last 10 years, the feasibility of rising the retirement age has also been promoted. ${ }^{4}$

Whether people are fulfilled with their jobs determines whether they are in favor of the retirement delay. And whether they feel fulfilled depends on their human capital and productivity. The blue-collar workers usually have fewer human capital and lower productivity. They feel less fulfilled with their jobs as their human capital depreciates and are inclined to depart from the labor market at a relatively young age. According to a poll carried by People's Daily Online, $68.6 \%$ of the respondents voted against rising the retirement age. ${ }^{5}$ But the high-skilled workers with more human capital and higher productivity, as their job fulfillment and wage rate are in a positive correlation with the growth of their human capital, tend to retire old. For example, the same poll showed that $31.4 \%$ of the respondents voted for rising the retirement age. ${ }^{5}$ Thus, a differentiated approach to delaying retirement, based on different human capital and productiveness, will get more endorsement.

Besides the differences in human capital, the efficiency of distributing labor forces and the employment pressures should be taken into consideration in choosing a better plan to delay retirement (Gendell 1998). If the oversupplied low-skilled manpower delay to retire, the labor market will not be obviously impacted by a crowing-out effect. The workers contribute a certain percentage of their salaries to the pension's fund pool every month. Therefore, the funding source of pensions will not be affected. Thus, if we can extend the retirement age according to the status of demand and supply of different labor forces, the pension crisis can be more properly dealt with.

However, in recent years, China's unemployment rate has exceeded the internationally accepted alarm level of $4 \%{ }^{6}$ From 2008 to 2013, the unemployment rates are $4.2,4.3,4.1,4.1$, and $4.1 \%{ }^{7}$ From now to 2035 , there will be a long period when China can enjoy demographic dividend. Labor supply during the 12th 5-year plan will surpass 900 million, so there will not be a shortfall of labor forces. Relevant data indicate that there will be 25 million people entering the urban labor market every year, but only 12 million can land jobs, which means there will be 10 million newly added people jobless in the labor market every year. ${ }^{8}$ Given the already tough and deteriorating employment situation, the crowding effect in employment should be given full consideration when choosing a proper plan to extend the retirement age (Gendell 1998). Since a differentiated approach to delaying retirement can cause smaller impacts than a uniformed approach, it should be served as a primary strategy.

So far, there is a heated debate among people from all walks of life especially the academia about which is a better plan of delaying retirement. After considering the 
diversity of human capital and the disequilibrium of labor force, this paper conduct an elaborate mathematical analysis and simulation comparison between different policy options of the retirement delay to study their capabilities of closing a large pension deficit, their crowing-out effect, and political feasibility. This could serve as a reference for the government to reform the pension system.

\section{Literature review}

Since China reformed its pension system into a combination of social pooling with individual accounts in 1995, the pension deficit is getting increasingly larger. From 2010 to 2012, the deficit was 1.7 trillion yuan, 2.2 trillion yuan, and 2.9 trillion yuan, respectively. ${ }^{91011}$ The deficit in 2013 is expected to be astonishingly 18 trillion yuan. ${ }^{12}$ The distressful financial record leaves Chinese authorities no wiggle room but to reform the system. A proposal made by Tsinghua University shows that China will become a super aging society in 2030, in which one social security retiree will be supported by two workers on average. In order to fix the shortage of pension funds, the proposal believes it is necessary to extend the retirement age to 65 years old. Zheng Bingwen, Director of Center for International Social Security Studies, affiliated to the Chinese Academy of Social Sciences, supports that it is a routine method adopted by the international community to deal with an aging population and an unavoidable way to close the pension gap. Yet, Cai Fang, Director of the Institute of Population and Labor Economics, affiliated to the Chinese Academy of Social Sciences, holds another view. He believes the retirement delay should not be a one-size-fits-all policy. A uniformed approach to extend the retirement age will put into a disadvantageous position the low-skilled manpower that do not have competitive human capital. He thinks that if the retirement delay were carried out, the high-skilled manpower that have an edge in human capital should take the brunt. Ren Haoning, a consultant at China Investment Consulting agency, holds a more pointed attitude toward the retirement delay, saying that it is a "rob Peter to pay Paul" strategy. If the retirement age is put off by a year, the pension deficit can be alleviated by 20 billion yuan a year, on the cost of additional 6-7 million people jobless. ${ }^{13}$ In the face of the worsening pension crisis and the high unemployment rate, what should the Chinese government do? There are heated discussions among some scholars about whether China should adopt a uniformed or a differentiated approach to the retirement delay.

Scholars hold different opinions on whether delaying retirement can deal with the pension crisis. Lin and Gong (2007) and Wang and Mi (2013) argue that if the retirement age is set at a low level, early retirement becomes prevalent, a pension crisis is likely to happen. Retirement age should be adjusted according to the changing life expectancy. Now, the retirement age of Chinese urban citizens is not only lower than that of Chinese rural citizens but also much lower than that of the urban citizens in most developed countries (Zhao 2009). Although extending the retirement age is not a panacea for the pension crisis, it could largely alleviate workers from the heavy pressures of paying insurance. For example, in Austria, the contribution rate of individuals to the pension program has been reduced about $8 \sim 14 \%$ after extending the retirement age (Jaag et al. 2010). However, Lei et al. (2010) argued that although the retirement delay should be carried out as soon as possible, a cookie-cutter approach should not be encouraged. People should be allowed to have more options about their retirement age on their own will. For instance, people who 
are willing to work longer can be allowed to retire late. Not only will it curtail the rising costs of public pensions but also address the looming labor shortages associated with an aging population (Van Dalen et al. 2010).

However, Weller (2002) argued that rising the retirement age will not contain the enlarging pension funding gap but reduce the pensions of low-income population. The result will run counter to the primary objectives of social security that aims to eliminate poverty of the aging population and narrow down the gap between the rich and poor. In fact, given that pensions are inheritable, the pension deficit is not necessarily connected with the aging population, and there are a few uncertainties about the effect of the retirement delay over the alleviation of the pension deficit (Zhang 2006). Yet, if we put the growing life expectancy into consideration, the pension gap will be in a correlation with the aging population. By extending retirement age, the social security program can pool more funds because people have to pay more money into their pension accounts for a longer time, which could offset the effect of the retirement delay over closing the pension gap (Zhang 2007).

However, according to our research, the effect of the retirement delay over closing the pension gap depends on the situation and accumulation of human capital of the insured. Low-skilled workers will find their human capital declining at older ages (Skirbekk 2008), so their contributions in their pension plans will decrease along with the wage rate. Extending their working life will not do anything good to address the pension crisis. For high-skilled workers, the human capitals are on an upward trajectory, so their contributions in their pension plans can increase with the wage rate. Extending their working life will help alleviate the pension crisis.

Even though the retirement delay is able to reduce the pension gap, its impact to the labor market cannot be ignored. Some experts have discussed this question. Li (1997) argues that unemployment rate is related to labor cost. Early retirement means the pensioners can enjoy a longer period of pension collection, which rise the labor cost. As a result, unemployment rate goes up. Thus, the retirement delay can mitigate employment pressures and the extension of life expectancy makes it feasible. As their life expectancy grows, the insured can get higher return on investment in human capital and become more willing to retire late (Lin and Gong 2007). From an empirical view, Hairault et al. (2010) analyze the boost of the retirement delay to employment. They argued that a low level of statutory retirement age would not only increase the unemployment rate of the insured before retirement but also make more new workers lose their job. The retirement delay can mitigate the structural contradiction created by the oversupply of labor force.

On the contrary, Martins et al. (2009) hold that the retirement delay does not generate as many benefits as the above research has shown. Given wage rigidity and employment protection laws, extending retirement age will have a crowding-out effect on employment. If the retirement delay is carried out holistically, enterprises, after putting into consideration the possible legal consequences and loss of profits, will have to cut headcounts for new recruits, so the employees who have been delayed retiring can continue occupying their original positions. This will result in a rise of unemployment rate. Ding and Lv (2014) believes that the impact of the retirement delay on employment and distribution of labor force varies based on individuals. On the one hand, if we can put off the retirement age of high-skilled manpower, their human capital can have a 
bigger play. On the other hand, if the low-skilled manpower can retire as scheduled, they can spare their jobs to more energetic new labor force entrants. This can increase the efficiency of distribution of labor force distribution. This paper also believes that in the process of deciding how to extend the retirement age, individuality warrants particular attention. Using a differentiated approach to extending retirement age can make a smaller impact on the labor market.

Through literature review, we can realize that there are basically two voices about whether and how to extend retirement age. Although some scholars have conducted research on human capital and some related issues, most of their works focus on an introspection of concrete issues and the current system. Few of them have tried to explore the interaction between the pension deficit and the labor market from the structural perspective. This paper will start from the heterogeneity of human capital and the disequilibrium of labor force and explore the dynamic of wage rate, unemployment rate, and job fulfillment, which are attached to the accumulation pattern of human capital, so that we can conduct a thorough model analysis and data simulation for the timing and effect of the retirement delay.

\section{Methods}

Research hypothesis and the model

Research hypothesis

H1: The fact that individual accounts are empty and only have the function of accounting indicates that the current pension system that features a combination of social pooling with individual accounts is still a pay-as-you-go mechanism. In their working years, the insured pay premiums $(\tau w)$ to the government on the basis of wage rates $(w)$. After retirement, they can get pensions that are distributed according to a uniform pension replacement rate $(\theta)$ and benchmarked against the social average wage rate $(w)$ during their working years. The mechanism of pay-as-you-go system, requiring the working people to support the retired, refers that the decline of population growth $(n)$ will definitely aggravate the crisis of pension deficit $(d)$. If the government does not want to thoroughly reform the current pension system into a fund, the insured will have to be delayed to retire in order to balance the budget.

$\mathrm{H} 2$ : The insured live two periods-the working years and the retirement, either of which is measured by a standard unit. The insured inelastically offer one unit of work during the working years, and the labor supply $(\delta)$ is decided by the substation relations $u$ between consumption $(c)$ and leisure (le), $0 \leq \delta<1$.

H3: The labor productivity of the insured varies according to different individuals. The labor productivity of the high-skilled workers is higher than that of the low-skilled workers; thus, the wage rate of the high-skilled is also higher than that of the lowskilled, i.e., wh $>w>$ wl. Labor productivity is related to human capital. The longer the high-skilled workers work, the more human capital they can gather. This is the other way around for low-skilled workers (Skirbekk 2008). Therefore, the labor productivity of the high-skilled workers will be increasingly high, but that of the low-skilled workers will be going down.

H4: The variation of the labor productivity is the root cause for the diversification of the wage rate, unemployment rate, and job fulfillment. The higher labor 
productivity the insured have, the higher wage rate and job fulfillment they can get, and the lower unemployment rate there will be. On the contrary, with lower labor productivity the insured have comes lower wage rate and job fulfillment and higher unemployment rate. Therefore, the insured who have higher labor productivity are inclined to rise the retirement age more deeply than the insured with lower labor productivity.

H5: The retirement delay has a crowding-out effect on new labor force (Gendell 1998). The longer the retirement delay is, the bigger the crowding-out effect will be, and the effect varies according to different individuals. Generally speaking, the retirement delay has little effect on the high-skilled workers whose unemployment rate $(e)$ is low but has much impact on low-skilled workers whose unemployment rate $(e)$ is usually high. Therefore, a differentiated approach to rise retirement age, allowing highskilled manpower to retire later than low-skilled manpower, can cause much softer crowding-out effect than a cookie-cutter approach to delay retirement.

\section{Modeling}

The utility function and constraint Utility is only related to consumption $(c)$, which is encompassed by two parts: consumption during working years $\left(c_{\mathrm{w}}\right)$ and consumption after retirement $\left(c_{\mathrm{r}}\right)$. The intertemporal consumption can be indicated by a separable logarithmic utility function.

$$
U\left(c_{\mathrm{w}}, c_{\mathrm{r}}\right)=1 \mathrm{n} c_{\mathrm{w}}+\frac{1}{1+\rho} \ln c_{\mathrm{r}}
$$

$\rho$ refers to the intertemporal consumption preference, and $\rho \geq 0$. Given the employment rate $(e)$, the consumption during working years $\left(c_{\mathrm{w}}\right)$ stems from the working reward $(w)$ with the premiums $(\tau w)$ and personal savings $(s)$ deducted, which is as follows:

$$
c_{\mathrm{w}}=(1-\tau)(1-e) w_{t-1}-S
$$

The consumption after retirement is more complicated than the consumption during working years. It includes personal savings and interests $(1+r) s$, pensions $(\theta w)$, and rewards acquired by working in retirement $\delta(1-\phi \tau) w$. The equation is as follows:

$$
c_{\mathrm{r}}=(1+r) s+\theta(1-e) \bar{w}_{t-1}+\delta(1-\phi \tau)(1-e) w_{t}-\frac{1}{2} \mu \delta^{2} .
$$

in which $w_{\mathrm{t}}$ is described as follows:

$$
\bar{w}_{t}=\frac{\sum_{i=h, l} N_{t} w_{t}^{i}+\bar{\delta} \sum_{i=h, l} N_{t}{ }_{t i} w_{t}^{i}}{\sum_{i=h, l} N_{t}+\bar{\delta} \sum_{i=h, l} N_{t}{ }_{t}}=\frac{\sum_{i=h, l} N_{t} w_{t} w_{t}^{i}}{\sum_{i=h, l} N_{t}} .
$$

During a crisis of pension deficit, the government will generally give tax preferences to the pensioners who choose to work in retirement in order to reduce the resistance on the retirement delay; thus, $0 \leq \phi<1$. Working in retirement will bring disutility $(\mu)$ to pensioners. The stronger the substitution effect leisure has on consumption, the higher cost we have to pay to increase consumption. Therefore, we put $1 / 2 \mu \delta^{2}$ in the 
consumption after retirement, which can reflect the resistance of the insured to the retirement delay.

The optimal length of time of working $\left(\delta^{\prime \prime}\right)$ if the insured choose to work in retirement The formulation to reflect the best decision by the insured who are in retirement is as follows:

$$
\underset{\delta}{\operatorname{Max} u}\left(c_{\mathrm{r}}\right)=\ln \left[(1+r) s+\theta(1-e) \bar{w}_{\mathrm{t}-1}+\delta(1-\phi \tau)(1-e) w_{\mathrm{t}}-\frac{1}{2} \mu \delta^{2}\right] . \quad \text { If the optimal }
$$

time of working for the insured $(\delta)$ satisfies

$$
\frac{(1-\phi \tau)(1-e) w_{t}-\mu \delta}{(1+r) s+\theta(1-e) \bar{w}_{t-1}+\delta(1-\phi \tau)(1-e) w_{t}-\frac{1}{2} \mu \delta^{2}}=0
$$

then the optimal length of time of working for the insured who choose to work in retirement is

$$
\delta *=(1-\phi \tau)(1-e) w_{t} / \mu .
$$

The effect of the retirement delay on pension deficit $(d)$ On the basis of the actuarial arrangement that the working population should support the retired population, in order to address the pension crisis caused by the aging population, if the retirement age is rised, the amount of pension deficit will be as follows:

$$
d_{t}=(1-\bar{e}) N_{t}^{\tau} \theta \bar{w}_{t-1}-\left[\tau \sum_{i=h, l}\left(1-e_{i}\right) N_{t} w_{l} w_{i}+\phi \tau \sum_{i=h, l}\left(1-e_{i}\right) N_{t} \delta_{t} \delta_{i} w_{i}\right] .
$$

In the equation, $N_{t}^{\mathrm{wh}}$ and $N_{t}^{\mathrm{wl}}$ respectively refer to the number of high-skilled workers and low-skilled workers, where $t$ refers to period of working years and $N_{t}^{\mathrm{rh}}$ and $N_{t}^{\mathrm{rl}}$ respectively refer to the high-skilled workers and low-skilled workers, where $t$ refers to period in retirement. $N_{t}$ (the number of the insured during their working years) and ${ }_{t}^{N}$ (the number of the insured in retirement) satisfy this equation: $N_{t}=(1+n) N_{t} \cdot w_{t}$ and $\mathrm{w}_{t}^{l}$ are the wage rates of high-skilled workers and low-skilled workers. The average wage rate $\overline{w_{t}}$ in the period $t$ and the average wage rate $\bar{w}_{\mathrm{t}-1}$ in the period $t-1$ satisfy the equation $\bar{w}_{t}=(1+g) \bar{w}_{t-1}$. Besides, the average unemployment rate $\bar{e}$ is

$$
\bar{e}=\sum_{i=h, l}\left(N_{t}^{w i}+N_{t}^{r i} \delta_{i}\right) e_{i} / \sum_{i=h, l}\left(N_{t}^{w i}+N_{t}^{r i} \delta_{i}\right) .
$$

The impact of unemployment rate $(e)$ on the retirement delay Assume in the period $t$, the total number of labor force is $N_{w}$, and the number of job opportunities is $T$. If the retirement is not delayed, i.e., $\delta=0$, the unemployment rate can be indicated as

$$
e=\left(N_{w}-T\right) / N_{w}=1-T / N_{w} .
$$

If the retirement is delayed, i.e., $\delta>0$, the unemployment rate can be modified as 


$$
e=\left[\left(N_{w}+\sum_{i=h, l} \delta_{i} N_{r}^{i}\right)-T\right] / N_{w}=1+\bar{\delta} /(1+n)-T / N_{w}
$$

in which $\bar{\delta}=\sum_{i=h, l} N_{t}^{r i} \delta_{i} / N_{t}^{r}$. Thus, the increment in unemployment rate $(\Delta e)$ due to the delayed retirement $(\delta)$ is

$$
\Delta e=\sum_{i=h, l} N_{t}^{r i} \delta_{i} / N_{w}=\bar{\delta} /(1+n) .
$$

\section{Selection mechanism of the retirement delay}

How to choose the right retirement plan under the restraint of pension deficit and unemployment

If we adopt a differentiated policy to rise retirement age $\left(\delta_{h} \neq \delta_{l}\right)$, we can acquire the overall marginal effect of the retirement delay $\left(\delta_{i}\right)$ on pension deficit $\left(d_{t}\right)$ based on Eq. 3

$$
\begin{aligned}
\sum_{i=h, l} \frac{\partial d_{t}}{\partial \delta_{i}} & =\frac{\partial d_{t}}{\partial \delta_{h}}+\frac{\partial d_{t}}{\partial \delta_{l}}=-\phi \tau \sum_{i=h, l}\left(1-e_{i 0}\right) N_{t}^{r i} w_{l} w_{l} \\
& =-\frac{\phi \tau}{1+n}\left[\sum_{i=h, l} N_{t} w_{t} w_{i}-\sum_{i=h, l} e_{i 0} N_{t}^{w i} w_{i}\right] .
\end{aligned}
$$

If we adopt a uniformed policy to rise retirement age $\left(\delta_{h}=\delta_{1}=\bar{\delta}\right)$, we can acquire the overall marginal effect of the retirement delay $(\bar{\delta})$ on pension deficit $\left(d_{t}\right)$.

$$
\begin{aligned}
\sum_{i=h, l} \frac{\partial d_{t}}{\partial \delta_{i}}=\frac{\partial d_{t}}{\partial \delta} & =-\phi \tau \sum_{i=h, l}\left(1-e_{i 1}\right) N_{t}^{r_{i}} w_{l} \\
& =-\frac{\phi \tau}{1+n}\left[\sum_{i=h, l} N_{t}^{w_{i}} w_{l}-\sum_{i=h, l} e_{i 1} N_{t}^{w_{i}} w_{l}\right] .
\end{aligned}
$$

Since $0<e<1$, so $\sum_{i=h, 1} d / \delta<0$. This means no matter which policy we adopt, a differentiated one or a uniformed one, the pension crisis can be relieved. However, according Eq. 4, the retirement delay can cause crowding-out effect on employment, which is illustrated in this equation:

$$
d(\Delta e) / d \bar{\delta}=1 /(1+n) .
$$

If $d(\Delta e) / \bar{d} \delta>0$, the retirement delay will increase the average unemployment rate (e). Besides, $\sum_{i=h, l} \partial d / \partial \delta_{i}$ will be bigger as $\bar{e}$ grows, indicating that the retirement delay results in the increase of unemployment rate, in which the situation will weaken its role in bridging the pension gap.

There is structural conflict in which there is an oversupply of low-skilled manpower and short supply of high-skilled workers. Low-skilled manpower's human capital will depreciate and the high-skilled manpower's human capital will appreciate in their retirements. Therefore, the unemployment rate of low-skilled workers is always higher than high-skilled workers whether in their working years or in retirement $\left(e_{1}>e_{\mathrm{h}}\right)$. Thus, the retirement delay can cause bigger crowding-out effect to low-skilled workers than high-skilled workers, which can be shown as the following: 


$$
\left|e_{l 1}-e_{l 0}\right|>\left|e_{h 1}-e_{h 0}\right|
$$

In the equation, $e_{10}$ and $e_{11}$ are, respectively, the unemployment rates of low-skilled workers when they are in the working years and retirement. $e_{\mathrm{h} 0}$ and $e_{\mathrm{h} 1}$ are, respectively, the unemployment rates of high-skilled workers when they are in the working years and retirement.

Since low-skilled workers occupy the majority of the labor market, if they have to retire at the same age as high-skilled workers, it might cause higher average unemployment rate.

$$
\frac{\sum_{i=h, l}\left(N_{t}^{w i}+N_{t}^{r i} \bar{\delta}\right) e_{i 1}}{\sum_{i=h, l}\left(N_{t}^{w i}+N_{l} \bar{\delta}\right)}>\frac{\sum_{i=h, l}\left(N_{t}^{w i}+N_{t}^{r i} \delta_{i}\right) e_{i 0}}{\sum_{i=h, l}\left(N_{t}^{w i}+N_{t}^{r i} \delta_{i}\right)} .
$$

A uniformed approach to rising retirement age $\left(\delta_{h}=\delta_{1}=\bar{\delta}\right)$ can increase the average unemployment rate $(\overline{\boldsymbol{e}})$. On the one hand, it can reduce the tax base of retirement pension premium, which is the weighted average wage rate $(\bar{w})$. On the other hand, it will cut down the source of contribution in the pension fund, which is the number of labor force who should pay premiums to their retirement portfolio $[(2+n)(1-\bar{e}) /(1+n)] N_{w}$. Therefore, with the growth of the crowding-out effect overemployment, a uniformed approach to rising retirement age will have weaker impact on closing pension deficit.

If we carry out a differentiated approach to rising retirement age $\left(\delta_{\mathrm{h}} \neq \delta_{\mathrm{l}}\right)$ based on the supply of labor force and the dynamic pattern of human capital, such as allowing high-skilled workers to retire later than low-skilled workers, it will not only reduce the impact over the labor market but also increase the tax base of retirement pension premium - the average wage rate. Therefore, the pension deficit can be better dealt with.

$$
\left|\partial d_{t} / \partial \delta_{h}+\partial d_{t} / \partial \delta_{l}\right|>\left|\partial d_{t} / \partial \bar{\delta}\right|
$$

Then,

$$
\sum_{i=h, l} e_{i 0} N_{t}^{w i} w_{t}<\sum_{i=h, l} e_{i 1} N_{t}^{w i} w_{t} .
$$

Thus, it can be concluded that in terms of reducing the crowing-out effect on employment, and closing the pension deficit, a differentiated approach to rise retirement age is better than a uniformed one.

\section{How to choose the right plan for the retirement delay based on political feasibility}

According to Eq. 2, we can take the derivative of $\delta$ with respect to $e$

$$
d \delta * / d e=-(1-\phi \tau) w_{t} / \mu .
$$

$d \delta^{*} / d e<0$ means that people's willingness to delay retirement is inversely proportional to unemployment rate $(e)$. If the unemployment rate grows increasingly higher, the insured will only agree to rise the retirement age in a smaller range. Since the unemployment rate of low-skilled workers is higher than that of the high-skilled workers, the low-skilled workers will not agree with a range of delay as wide as the high-skilled workers. 
According to Eq. 2, we can take the derivative of $\delta$ with respect to $w$

$$
d \delta * / d w=-(1-\phi \tau)(1-e) / \mu .
$$

$d \delta^{*} / d w>0$ means people's willingness to rise retirement age is positively correlated with wage rate $(w)$. The insured will agree with a wider range of delay if their wage rate is higher. Since the human capital of low-skilled workers will depreciate as they get older, their wage rate will accordingly decline, so they will become less willing to delay retirement. But since the human capital of high-skilled workers will grow stronger as they get older, their wage rate will accordingly increase, so they will become more willing to retire later.

According to Eq. 2, we can take the derivative of $\delta$ with respect to $\mu$

$$
d \delta * / d \mu=-(1-\phi \tau)(1-e) w_{t} / \mu^{2}
$$

$d \delta * / d \mu>0$ means that people's willingness of delaying retirement is inversely proportional to the substitution effect of leisure on consumption $(\mu)$. The bigger the substitution effect is (work brings bigger negative impact), the fewer years of rise $(\delta)$ the insured will agree on. Since their human capital depreciates as they get older, lowskilled workers will feel less fulfillment and social approval degree by doing their jobs, so they will be increasingly unwilling to delay retirement. But high-skilled workers will feel the opposite by doing their jobs because their human capital can increase as they get older, so they will be more willing to retire later.

Based on the analysis above, people's preference of the retirement delay is closely associated with unemployment rate, wage rate, and the substitution effect of leisure on consumption. Given the fact that the unemployment rate and the substitution effect of high-skilled workers are smaller than those of low-skilled workers, and that the former's wage rate is higher than that of the latter's, it is more politically feasible to adopt a differentiated plan of the retirement delay featuring high-skilled workers retire much later than low-skilled workers, compared with a uniformed approach to raising retirement age.

\section{Results and discussion}

\section{Data simulation}

\section{Simulation analysis of the impact of the retirement delay on pension deficit}

Table 1 shows that by raising retirement age $(\delta)$, we can reduce the number of retirees to reduce the pension deficit $(d)$, but the effect will be restrained by the crowding-out effect of employment. The more new workers crowded out by the retirement delay, the less pension deficit it can reduce. Since the great retirement delay and the uniform delay can pile out more workers than minor retirement delay and differentiated

Table 1 The retirement delay's overall marginal effect on pension deficit

\begin{tabular}{llllllllllllll}
\hline Plans & $\Phi$ & $\tau$ & Number & $e_{h 0}$ & $e_{10}$ & $N_{\mathrm{wh}}$ & $N_{\mathrm{tw}}$ & $N_{\mathrm{th}}$ & $N_{t}$ & $w_{t}^{h}$ & $w_{t}^{l}$ & $\frac{\partial d}{\partial \delta_{h}}+\frac{\partial d}{\partial \delta_{l}}$ \\
\hline A & A1 & 0.8 & 0.28 & 0.005 & 0.12 & 0.26 & 0.1 & 0.9 & 0.05 & 0.45 & 0.6 & 0.3 & -0.0563 \\
& A2 & 0.8 & 0.28 & 0.005 & 0.11 & 0.23 & 0.1 & 0.9 & 0.05 & 0.45 & 0.6 & 0.3 & -0.0582 \\
B & B1 & 0.8 & 0.28 & 0.005 & 0.12 & 0.3 & 0.1 & 0.9 & 0.05 & 0.45 & 0.6 & 0.3 & -0.0539 \\
& B2 & 0.8 & 0.28 & 0.005 & 0.11 & 0.25 & 0.1 & 0.9 & 0.05 & 0.45 & 0.6 & 0.3 & -0.0571 \\
\hline
\end{tabular}

$A$ differentiated plan, $A 1$ great retirement delay, $A 2$ slight retirement delay; $B$ uniform plan, $B 1$ uniform plan with more delay, $B 2$ uniform plan with less delay 
retirement delay, so the former two approaches will not decrease the pension deficit as expected. It shows that, on the one hand, longer retirement delay is not necessarily appropriate, and on the other hand, we cannot adopt a cookie-cutter approach to promoting retirement delay, instead, we must choose a proper program of retirement delay based on different employment situations of different groups.

\section{Simulation analysis of the impact of retirement delay on unemployment rate}

Table 2 indicates that the crowding-out effect on new workers $(\Delta e)$ caused by a longer retirement delay and a uniformed retirement delay is respectively greater than a shorter retirement delay and a differentiated retirement delay. Retirement delay $(\delta)$ means the older generations will keep occupying the jobs that are supposed to be handed over to younger generations. The longer we delay retirement, the more jobs the older generations can occupy. Before delaying retirement, we have to consider the adaptability of the labor market in the face of the crowding-out effect on employment (Gendell 1998). The more flexible the labor market is, the longer we can delay retirement, and vice versa. Rising the retirement age of the oversupplied low-skilled workers in a lesser margin and rising the retirement age of the under-supplied high-skilled workers in a greater margin can alleviate the imbalance of the supply-demand structure of labor force. Besides, since more low-skilled workers than high-skilled workers will be crowded out after retirement delay, the impact of retirement delay on employment depends on the proportion of low-skilled workers in the entire population. With higher proportion of low-skilled workers in the entire population comes more workers being crowded out. Thus, to reduce the proportion of low-skilled workers and help them increase their human capital to become high-skilled workers and have higher productivity is essential to a feasible plan of rising retirement age.

\section{Simulation analysis of the feasibility of different plans of retirement delay}

Table 3 shows that under the circumstances of low unemployment rate, high wage rate, and low substitution effect, the insured can accept longer retirement delay than under the circumstances of high unemployment rate, low wage rate, and high substitution effect.

First, the preference of the insured for retirement delay $(\delta)$ is inversely proportional to unemployment rate $(e)$. The insured prefer shorter retirement delay if the unemployment rate is high, and vice versa. The tendency indicates that it is politically feasible to allow shorthanded high-skilled workers to retire much later than the oversupplied low-skilled workers.

Second, the preference of the insured for retirement delay is proportional to wage rate $(w)$. The insured prefer longer retirement delay if their wage rate is high and vice versa. This indicates that more people will approve that high-skilled workers with high wage rate can retire later than low-skilled workers with low wage rate.

Table 2 The impact of retirement delay on unemployment rate

\begin{tabular}{llllllllll}
\hline Plans & & $\delta h$ & $\delta l$ & Number & $N_{w h}$ & $N_{w 1}$ & $N_{t h}$ & $N_{t}$ & $\Delta e$ \\
\hline A & A1 & 0.7 & 0.5 & 0.005 & 0.1 & 0.9 & 0.05 & 0.45 & 0.26 \\
& A2 & 0.4 & 0.2 & 0.005 & 0.1 & 0.9 & 0.05 & 0.45 & 0.11 \\
B & B1 & 0.7 & 0.7 & 0.005 & 0.1 & 0.9 & 0.05 & 0.45 & 0.35 \\
& B2 & 0.4 & 0.4 & 0.005 & 0.1 & 0.9 & 0.05 & 0.45 & 0.21 \\
\hline
\end{tabular}

$A$ differentiated plan, $A 1$ longer retirement delay, $A 2$ shorter retirement delay, $B$ uniform plan, $B 1$ uniform plan with longer delay, $B 2$ uniform plan with shorter delay 
Table 3 Preference of the insured for retirement delay

\begin{tabular}{|c|c|c|c|c|c|c|c|c|c|c|c|c|}
\hline Background & & $\mu$ & $\Phi$ & $\tau$ & Number & e & $N_{\text {wh }}$ & $\mathrm{N}_{\mathrm{wl}}$ & $\mathrm{N}_{\mathrm{th}}$ & $\mathrm{N}^{\mathrm{t}}$ & $w_{t}$ & $\delta^{*}$ \\
\hline \multirow[t]{2}{*}{ Low unemployment rate } & High-skilled workers & 1 & 0.8 & 0.28 & 0.005 & 0.11 & 0.1 & 0.9 & 0.05 & 0.45 & 0.6 & 0.4144 \\
\hline & Low-skilled workers & 1 & 0.8 & 0.28 & 0.005 & 0.25 & 0.1 & 0.9 & 0.05 & 0.45 & 0.3 & 0.1746 \\
\hline \multirow[t]{2}{*}{ High unemployment rate } & High-skilled workers & 1 & 0.8 & 0.28 & 0.005 & 0.12 & 0.1 & 0.9 & 0.05 & 0.45 & 0.6 & 0.4097 \\
\hline & Low-skilled workers & 1 & 0.8 & 0.28 & 0.005 & 0.3 & 0.1 & 0.9 & 0.05 & 0.45 & 0.3 & 0.1629 \\
\hline \multirow[t]{2}{*}{ Low wage rate } & High-skilled workers & 1 & 0.8 & 0.28 & 0.005 & 0.11 & 0.1 & 0.9 & 0.05 & 0.45 & 0.4 & 0.2763 \\
\hline & Low-skilled workers & 1 & 0.8 & 0.28 & 0.005 & 0.25 & 0.1 & 0.9 & 0.05 & 0.45 & 0.2 & 0.1164 \\
\hline \multirow[t]{2}{*}{ High wage rate } & High-skilled workers & 1 & 0.8 & 0.28 & 0.005 & 0.11 & 0.1 & 0.9 & 0.05 & 0.45 & 0.6 & 0.4144 \\
\hline & Low-skilled workers & 1 & 0.8 & 0.28 & 0.005 & 0.25 & 0.1 & 0.9 & 0.05 & 0.45 & 0.3 & 0.1746 \\
\hline \multirow[t]{2}{*}{ Low substitution effect } & High-skilled workers & 1 & 0.8 & 0.28 & 0.005 & 0.11 & 0.1 & 0.9 & 0.05 & 0.45 & 0.6 & 0.4144 \\
\hline & Low-skilled workers & 0.7 & 0.8 & 0.28 & 0.005 & 0.25 & 0.1 & 0.9 & 0.05 & 0.45 & 0.3 & 0.2494 \\
\hline \multirow[t]{2}{*}{ High substitution effect } & High-skilled workers & 2 & 0.8 & 0.28 & 0.005 & 0.11 & 0.1 & 0.9 & 0.05 & 0.45 & 0.6 & 0.2072 \\
\hline & Low-skilled workers & 1.2 & 0.8 & 0.28 & 0.005 & 0.25 & 0.1 & 0.9 & 0.05 & 0.45 & 0.3 & 0.1455 \\
\hline
\end{tabular}


Third, the preference of the insured for retirement delay is inversely proportional to the substitution effect $(\mu)$. For the insured, the higher the substitution effect is, the less tolerant they will be to retirement delay and vice versa. This indicates that as time passes, the human capital of the low-skilled workers will depreciate, and they will feel increasingly unfulfilled with their payment and jobs. So they will prefer a shorter retirement delay. However, the high-skilled workers are in a different case. As their human capital will accumulate and ramp up, the high-skilled workers will feel increasingly fulfilled with the payment and their jobs. So they will prefer a longer retirement delay. Thus, it is more politically feasible to allow high-skilled workers with low substitution effect to retire later than low-skilled workers with high substitution effect.

In fact, the impact of unemployment rate, wage rate, and substitution effect on people's preference for retirement delay is related to the human capital of the insured. The insured with more high-quality human capital prefer a longer retirement delay. In order to address an aging population and the pension deficit, and persuade the insured to work longer than their older generations, we must start from the investment in human capital. The only way to improve the political feasibility of the pension reform should be to ratchet up the productivity and job fulfillment of the insured, especially the lowskilled workers.

\section{Conclusions}

Starting from the interaction between the pension deficit and the labor market, this paper has offered a detailed mathematical analysis and simulation comparison with regard to the selection mechanism of retirement delay plans, the effect of reducing pension deficit, and the crowding-out effect on employment and political feasibility.

This research has found that early retirement under the circumstance of aging population is a major contributor to pension deficit. Retirement delay can reduce the deficit, but the effect is in an inverted U-shaped trajectory. The reduction of the pension deficit due to the retirement delay will become smaller when it reaches a certain level. A longer retirement delay does not necessarily mean better results.

The effect of retirement delay on reducing pension deficit is restricted by the crowdout effect on employment (Gendell 1998). Extending workers' retirement age will crowd out new employees. The longer the extension is, the more new employees will be crowded out. Besides, the crowding-out effect is different in various cases. Generally speaking, short-handed high-skilled employees will be less affected, but the oversupplied low-skilled employees will be affected significantly. No matter how the crowdingout effect on employment varies in different groups of people, retirement delay will definitely increase unemployment rate and reduce the tax base (average wage rate) of pension levy, which will compromise the reduction of pension deficit.

In fact, human capital and individual differences are related to retirement delay's effect on reducing pension deficit and crowding out new employees. If the insured have more high-quality human capital, the retirement delay can reduce pension deficit more significantly and have less effect on new employees. Generally speaking, as for lowskilled workers, due to a lack of human capital which will depreciate as their working years grow (Skirbekk 2008), they will be significantly impacted by retirement delay. The source of pensions will become more limited along with the rise of unemployment rate and the decrease of wage rate, which will deeply compromise the effect of retirement 
delay on closing the gap of pension deficit. But as for high-skilled workers, since they have more high-quality human capital which can appreciate as their working years grow, retirement delay will insignificantly affect their real life. The source of pensions will become prosperous along with the decrease of unemployment rate and the rise of wage rate, which will contribute to the reduction of pension deficit.

However, no matter what effect can the retirement plan have on reducing pension deficit and the labor market, without the endorsement of the majority of the insured, the policy of rising retirement age will not be carried out. The preference of the insured for retirement delay is proportional to the fluctuation of wage rate, while inversely proportional to the unemployment rate and substitution effect. Since the high-skilled workers have higher wage rate, lower unemployment rate, and the substitution effect of leisure against consumption is small, they will feel more fulfilled with working as their human capital accumulates and appreciates, so they are inclined to retire later. Since the low-skilled workers have lower wage rate, high unemployment rate, and their substitution effect of leisure against consumption is large, they will feel less fulfilled with working as their human capital depreciates, so they are inclined to retire early or at least on time. Therefore, we should differentiate the retirement age based on education background, work experience, technical training, and professions of the insured. For example, university professors, surgeons, and research scientists can be allowed to retire later than physical laborers such as construction workers. In this way, retirement delay will not face much political resistance.

Based on the above research, from the perspective of the length of retirement delay, a shorter retirement delay can have reduce pension deficit better than a longer retirement delay and have less effect on the labor market. From the perspective of choosing the right retirement plan, a differentiated approach to rise retirement age can produce results better than a uniform approach. Not only can the differentiated approach crowd out fewer new employees, but also it can acquire support from the majority of the insured. Regardless of the length and type of the retirement delay, we must attach importance to the role of human capital investment in addressing pension and employment crises. It is the only path to rise the economic efficiency and political feasibility of retirement delay by strengthening vocational training and college education for the insured, especially for low-skilled workers (Qing 2011).

\section{Endnotes}

${ }^{1}$ The annual incremental data over the years about pension deficit from the Ministry of Finance.

${ }^{2}$ China's Ministry of Civil Affairs (2012). The statistical bulletin on the development of social services in 2012; http://politics.people.com.cn.

${ }^{3}$ China's State Council (1978). Interim measures for the resettlement of sick and elderly cadres and interim measures for the resettlement of retirement and resignation.

${ }^{4}$ WHO (2013). World Health Statistics 2013. Global Times, http://www.huanqiu.com.

${ }^{5}$ Jia Y (2013). Nearly $70 \%$ of respondents opposed to delay retirement, $73.5 \%$ support flexible retirement. http://politics.people.com.cn.

${ }^{6} \mathrm{Li}$ YN (2010). Macroeconomic regulation and control line: the unemployment rate and the inflation rate are $4 \%$, the Shenzhen business daily, http://www.sznews.com. 
${ }^{7}$ China's National Bureau of Statistics (2013). China Statistical Yearbook 2013, http://www.stats.gov.cn.

${ }^{8} \mathrm{Li}$ H (2013). Delay retirement will not affect employment? People's Daily, http://paper.people.com.cn.

${ }^{9}$ World Social Security Research Center of Chinese Academy of Social Sciences (2011). China Pension Report 2011, http://www.cnss.cn.

${ }^{10}$ World Social Security Research Center of Chinese Academy of Social Sciences (2012). China Pension Report 2012, http://www.cnss.cn

${ }^{11}$ World Social Security Research Center of Chinese Academy of Social Sciences (2013). China Pension Report 2013, http://www.cnss.cn

${ }^{12} \mathrm{Cao} \mathrm{YH}$ and $\mathrm{Ma} \mathrm{J}$ (2013). To resolve the long-term risk of national assets and liabilities, http://finance.chinanews.com.

${ }^{13}$ Xia Y (2013). The strategy of retirement delay can increase 40 billion pension, which was awarded as a combat to poison with poison, http://finance.people.com.cn.

\section{Acknowledgements}

This article is supported by the Foundation for the Young Talents by Zhejiang Gongshang University (No: QY1521); Applied Economics Program of a key research institute of humanities and social science in the universities of Zhejiang Province (No: JYTyyjj201503RC); and the High Level Introduction of Talent Research Start-Up Fund by Zhejiang Gongshang University (No: 31-15-54).

Author details

${ }^{1}$ School of Economics, Zhejiang Gongshang University, Hangzhou, China. ${ }^{2}$ School of Economics, Zhejiang University, Hangzhou, China.

Received: 11 July 2016 Accepted: 24 August 2016

Published online: 08 October 2016

References

Blöndal S, Scarpetta S (1997) Early retirement in OECD countries: the role of social security systems. OECD Econ Stud 29(2):7-54

Ding Y, LV XJ (2014) Raising retirement age and developing high-skilled elder talent resources: mechanism and system design. Population and Development (Renkou yu Fazhan) 20(1):50-60

Gendell M (1998) Trends in retirement age in four countries, 1965-95. Monthly Lab Review 121(8):20-30

Hairault J, Langot F, Sopraseuth T (2010) Distance to retirement and older workers 'employment: the case for delaying the retirement age. J Eur Econ Assoc 8(5):1034-1076

Jaag C, Keuschnigg C, Keuschnigg M (2010) Pension reform, retirement, and life-cycle unemployment. Int Tax Public Financ 17(5):556-585

Lei XY, Tan L, Zhao YH (2010) Does retirement affect health? China Economic Quarterly (Jingjixue Jikan) 9(4):1539-1558

Li Z (1997) Economic thinking of retirement. Economic Review (Jingji Pinglun) 1:87-92

Lin ZJ, Gong LT (2007) Schooling, retirement, and social security. China Economic Quarterly (Jingjixue Jikan) 7(1):211-230

Martins P, Novo Á, Portugal P (2009) Increasing the legal retirement age: the impact on wages, worker flows and firm performance, IZA working paper, No. 4187

Qing SS (2011) Gender discrimination in job promotion. Management World (Guanli Shijie) 11:28-38

Skirbekk V (2008) Age and productivity capacity: descriptions, causes and policy options. Ageing Horizons 8:4-12

Song SB (2010) Actuarial valuation of implicit debt and fund operating conditions in social health insurance system. Management World (Guanli Shijie) 8:169-170

Van Dalen H, Henkens K, Henderikse W et al (2010) Do European employers support later retirement? Int J Manpow 31(3):360-373

Wang XJ, Mi HJ (2013) Pension payment gap: caliber and measurement analysis. J Quant Tech Econ (Shuliangjingji Jishujingji Yanjiu) 10:49-62

Weller C (2002) Don't raise the retirement age. Challenge 45(1):75-87

Xu CK, Qi ST, Shao XL, Liu SF (2003) Several policy recommendations to improve the social security system of China. Management World (Guanli Shijie) 1:137-138

Zeng Y (2005) China's population aging, deficit of retirement funds, and old age insurance program in rural areas. China Economic Quarterly (Jingjixue Jikan) 4(4):1043-1066

Zhang Y (2006) Quantitative analysis of the relationship between the heritage amount and the divisor factor of IRA. J Quant Tech Econ (Shuliangjingji Jishujingji Yanjiu) 23(12):126-134

Zhang Y (2007) On the IRA's solvency in Chinese pension system. J Quant Tech Econ (Shuliangjingji Jishujingji Yanjiu) 24(7):126-134

Zhao, Y. H. (2009), The Second International Symposium on Chinese Health and Retirement. News Letter of National School of Development, 66. 